\title{
Decavanadate interactions with actin: Inhibition of G-actin polymerization and stabilization of decameric vanadate
}

\author{
Susana Ramos ${ }^{\text {a,b }}$, Miguel Manuel ${ }^{\text {a,c }}$, Teresa Tiago ${ }^{\text {a,b,e }}$, Rui Duarte ${ }^{\mathrm{d}}$, Jorge Martins ${ }^{\text {a,c }}$, \\ Carlos Gutiérrez-Merino e, José J.G. Moura d, Manuel Aureliano a,b,* \\ a Dept. Química e Bioquímica, FCT, Universidade do Algarve, Faro, Portugal \\ ${ }^{\mathrm{b}}$ Centre for Marine Sciences (CCMAR), Universidade do Algarve, Faro, Portugal \\ ${ }^{\mathrm{c}}$ CBME, Universidade do Algarve, Faro, Portugal \\ ${ }^{\mathrm{d}}$ Dept. Química, FCT, Universidade Nova de Lisboa, Monte da Caparica, Portugal \\ ${ }^{\text {e }}$ Dept. Bioquímica y Biología Molecular, Facultad de Ciencias, Universidad de Extremadura, Badajoz, Spain
}

\begin{abstract}
Decameric vanadate species (V10) inhibit the rate and the extent of G-actin polymerization with an IC50 of $68 \pm 22 \mu \mathrm{M}$ and $17 \pm 2 \mu \mathrm{M}$, respectively, whilst they induce F-actin depolymerization at a lower extent. On contrary, no effect on actin polymerization and depolymerization was detected for $2 \mathrm{mM}$ concentration of "metavanadate" solution that contains ortho and metavanadate species, as observed by combining kinetic with ${ }^{51} \mathrm{~V}$ NMR spectroscopy studies. Although at $25^{\circ} \mathrm{C}$, decameric vanadate $(10 \mu \mathrm{M})$ is unstable in the assay medium, and decomposes following a first-order kinetic, in the presence of G-actin (up to $8 \mu \mathrm{M}$ ), the half-life increases 5-fold (from 5 to $27 \mathrm{~h})$. However, the addition of ATP $(0.2 \mathrm{mM})$ in the medium not only prevents the inhibition of G-actin polymerization by V10 but it also decreases the half-life of decomposition of decameric vanadate species from 27 to $10 \mathrm{~h}$. Decameric vanadate is also stabilized by the sarcoplasmic reticulum vesicles, which raise the half-life time from 5 to $18 \mathrm{~h}$ whereas no effects were observed in the presence of phosphatidylcholine liposomes, myosin or G-actin alone. It is proposed that the "decavanadate" interaction with G-actin, favored by the G-actin polymerization, stabilizes decameric vanadate species and induces inhibition of G-actin polymerization. Decameric vanadate stabilization by cytoskeletal and transmembrane proteins can account, at least in part, for decavanadate toxicity reported in the evaluation of vanadium (V) effects in biological systems.
\end{abstract}

\section{Introduction}

Widely known for its toxic effects, vanadium is vestigial in muscle and other tissues, being considered an essential oligoelement for humans, although its role is far from a clear identification [1-3]. Skeletal muscle cells and vanadium are strongly connected to each other, since it is known that ATP obtained from horse skeletal muscle really contains vanadium $[4,5]$. Thereafter, vanadium has a variety of physiological effects acting either as a phosphate analogue in the monomeric form $\left(\mathrm{H}_{2} \mathrm{VO}_{4}^{-}\right)$or through oligomeric vanadate species. Thus, vanadium showed to be a powerful biochemical tool to gain a deeper knowledge in several biochemical mechanisms such as the regulation of muscle contraction and the modulation of the F-actin stimulated myosin ATPase activity and its relevance to actin-myosin interactions [6,7].

In vanadium (V) solutions, different oligomeric vanadate species can occur simultaneously in equilibrium, e.g. monomeric (V1), dimeric (V2), tetrameric (V4) and decameric (V10) and, in some cases, with different states of 
protonation and structures, depending on several factors such as vanadate concentration, $\mathrm{pH}$ and ionic strength [8-10]. However, this vanadium polymorphism is not taken into consideration in most biological studies, although it is recognized that the individual species may have different effects on enzyme activities [11-14]. Furthermore, the rapid chemical equilibrium between vanadate oligomers, in the time scale of milliseconds [15], further complicates the identification of the vanadate species responsible for the effects promoted in biological systems. To this end a combination of biochemical kinetic studies with ${ }^{51} \mathrm{~V}$ NMR spectroscopy has proven to be very valuable $[12,14,16]$, as it allows correlating inhibitory effects with specific vanadate species distribution in solution $[12,14]$. Therefore, it is of primary importance to characterize precisely the vanadate species and the interactions with the system before attempting to understand the promoted effects [17].

To our knowledge, it is not possible to prevent the formation of decameric vanadate upon acidification of vanadate solutions, even at the micromolar concentration range. In fact, many researchers working in different areas ranging from life sciences to chemical engineering, using vanadate in their studies, frequently observed the orange/ yellow color in their solutions. This is due to the occurrence of decameric vanadate; for instance in a cell culture, after an acidification procedure during protein purification, after the adjustment of the $\mathrm{pH}$ value of the reaction medium or even in methods for vanadate quantification. Once formed, decameric vanadate decomposition is in general slow enough, to allow the study of its effects even in the micromolar range $[7,18]$. However, it may become inaccessible to deoligomerization due to their stabilization upon binding to target macromolecular structures [19]. Recent work from our laboratory [20-23] demonstrated that an acute exposure to decameric vanadate species, but not exposure to monomeric vanadate, induces changes on vanadium accumulation and in overall stress markers. Altogether, these observations reveal that decameric vanadate plays an important role in the evaluation of vanadium $(\mathrm{V})$ toxicity in biological systems [17].

Monomeric actin, G-actin, polymerizes to F-actin, the major component of cytoskeletal microfilaments in nonmuscle cells and of thin filaments in muscle cells. For all eukaryotic cells alterations of the G-actin/F-actin equilibrium will affect a wide variety of biological processes of high relevance for cell life such as locomotion, cytokinesis, phagocytosis and the acrossomal process of sperm [24].

It has been described that vanadate stabilizes F-actin filaments through the formation of F-actin-ADP.Vi complexes [24] and it induces actin polymerization by inhibiting specific tyrosine phosphatases [25]. It was recently reported some vanadate effects on actin polymerization including sperm capacitation, detachment of pathogenic microorganisms and chemotherapy of solid tumors [25-27]. In plant cells it has been described that vanadate (up to $4 \mathrm{mM}$ ) inhibits cell elongation due to the disruption of actin microfilaments [28]. At neutral $\mathrm{pH}$ and through the millimolar range of vanadate concentrations most frequently employed in those biochemical studies, the predominant vanadate species are not only the monomeric $\left(\mathrm{H}_{2} \mathrm{VO}_{4}^{-}\right)$, but also others vanadate oligomers such as dimeric $\left(\mathrm{H}_{3} \mathrm{~V}_{2} \mathrm{O}_{7}^{-}\right)$and cyclic tetrameric forms $\left(\mathrm{V}_{4} \mathrm{O}_{12}^{4-}\right)$ [8]. Besides, upon medium acidification, decameric vanadate species may also occur. Therefore, the putative effects of the different vanadate oligomers in actin structure and function are still to be clarified and to our knowledge have not been done yet. Using actin from rabbit skeletal muscle we report the effects of a decavanadate solution on the capacity of actin to polymerize. Our results suggest that decameric vanadate interactions with actin inhibit G-actin polymerization and stabilize decameric vanadate species.

\section{Materials and methods}

\subsection{Vanadate solutions}

Metavanadate solution $(50 \mathrm{mM}, \mathrm{pH} 6.0-7.0)$ was prepared from ammonium metavanadate $\left(\mathrm{NH}_{4} \mathrm{VO}_{3}\right)$ purchased from Riedel-de-Haen. Decavanadate solution was prepared in a manner that maximized the proportion of vanadate present as the decamer, by adjusting the $\mathrm{pH}$ of the metavanadate solution to 4.0 [29]. The presence of decameric vanadate species was revealed by a characteristic orange color. Both solutions were kept at $4{ }^{\circ} \mathrm{C}$. Decavanadate solutions were always ascertained to $\mathrm{pH} 6.0$, immediately before using. Wherever adjustable, decavanadate solutions were added to the assays from the concentrated or from a 10 -fold dilution of the stock solutions.

\subsection{Proteins and vesicles preparations}

Actin was extracted from acetone powder of rabbit skeletal muscle in buffer $\mathrm{G}$ [Tris $2 \mathrm{mM}$, pH 8.0, ATP $0.2 \mathrm{mM}$, $\mathrm{CaCl}_{2} 0.2 \mathrm{mM}, \beta$-mercaptoethanol $0.5 \mathrm{mM}, \mathrm{NaN}_{3} 0.005 \%$ ] as described by Pardee and Spudich [30]. G-actin $\left(M_{\mathrm{r}}\right.$ 42,300 ) concentration was determined by measuring absorbance at $290 \mathrm{~nm}$ using an extinction coefficient of $0.617 \mathrm{mg}^{-1} \mathrm{~mL} \mathrm{~cm}^{-1}$ [31]. Myosin was prepared from leg and dorsal rabbit skeletal muscle, as previously described by Pires et al. [32]. Myosin subfragment-1 (S1), was prepared as indicated in Tiago et al. [7]. S1 $\left(M_{\mathrm{r}} 115,000\right)$ concentration was determined spectrophotometrically by using an extinction coefficient of $\varepsilon_{280}^{1 \%}=7.5 \mathrm{~cm}^{-1}$.

Sarcoplasmic reticulum vesicles (SRV) were prepared from white skeletal rabbit muscle as described elsewhere [29]. Isolated SRV suspended in $\mathrm{KCl} 0.1 \mathrm{M}$, Tris $10 \mathrm{mM}$, $\mathrm{pH}$ 7.0, were diluted 1:1 with sucrose $2 \mathrm{M}$ and frozen in liquid nitrogen prior to storage at $-80{ }^{\circ} \mathrm{C}$. Protein concentration was determined by the biuret method, using bovine serum albumin as a standard [33]. The percentage of each protein present in the SRV preparations was determined through densitometry analysis of sodium dodecyl sulphate (SDS)-polyacrylamide gel electrophoresis (7.5\% acrylamide). The SR $\mathrm{Ca}^{2+}$-ATPase analyzed by 
SDS-polyacrylamide gel electrophoresis was at least 54\% of the total protein in SRV.

Liposomes were prepared according to a modified protocol from the standard method revised by Szoka and Papahadjopoulos [34]. POPC (1-palmitoyl-2-oleoyl-snglycero-3-phosphocholine) was obtained from Avanti Polar-Lipids (purity $>99.9 \%$ ) and a $5 \mathrm{mM}$ stock solution in a chloroform:methanol (2:1) solvent was prepared, $0.5 \mathrm{ml}$ of the stock solution were dried using a rotary evaporator Heidolph VV-micro and a vacuum pump Büchi V500 (with a V-800 vacuum control) during approximately $1 \mathrm{~h}$. The resulting lipid film on the flask walls was hydrated at $30^{\circ} \mathrm{C}$ (well above the main phase transition temperature of POPC, $-2{ }^{\circ} \mathrm{C}$ ) for about $1 \mathrm{~h}$ and vortexed regularly to produce a suspension with multilamellar vesicles. An aqueous buffer of Tris $2 \mathrm{mM}, \mathrm{pH} 7.5$, was used for hydration with a volume of $5 \mathrm{ml}$ added to the flask to obtain a final POPC concentration of $0.5 \mathrm{mM}$.

\subsection{Kinetic studies}

The kinetics of dissociation of decameric species was determined from measurements of the absorption at $400 \mathrm{~nm}$ (an absorption band which is characteristic of decameric vanadate), using a Shimadzu UV-2401PC spectrophotometer with $100 \mu \mathrm{M}$ total vanadate concentration, i.e. $10 \mu \mathrm{M}$ decameric vanadate species, in the several experimental medium conditions used in this study. Proteins or liposomes, wherever indicated, were added $(1,2,4$ and $8 \mu \mathrm{M})$ just before starting the measurements. Several reaction media were used: G-actin : $(2 \mathrm{mM}$ Tris, $0.2 \mathrm{mM} \mathrm{CaCl}$, $10 \mu \mathrm{M}$ ATP, $100 \mathrm{mM} \mathrm{KCl}, 2 \mathrm{mM} \mathrm{MgCl} 2, \mathrm{pH} 7.5 ; 2 \mathrm{mM}$ Tris, $0.2 \mathrm{mM} \mathrm{CaCl}, 0.2 \mathrm{mM}$ ATP, $100 \mathrm{mM} \mathrm{KCl}$, $2 \mathrm{mM} \mathrm{MgCl} 2, \mathrm{pH} 7.5$; and $2 \mathrm{mM}$ Tris, $0.2 \mathrm{mM} \mathrm{CaCl}$, $0.2 \mathrm{mM}$ ATP, pH 7.5) and F-actin ( $2 \mathrm{mM}$ Tris, $0.2 \mathrm{mM}$ $\mathrm{CaCl}_{2}, 10 \mu \mathrm{M}$ ATP, $100 \mathrm{mM} \mathrm{KCl}, 2 \mathrm{mM} \mathrm{MgCl} 2, \mathrm{pH} 7.5$ ); myosin S1 (2 mM Tris, $0.2 \mathrm{mM} \mathrm{CaCl} 2,0.2 \mathrm{mM}$ ATP, pH 7.5); liposomes ( $2 \mathrm{mM}$ Tris, $\mathrm{pH}$ 7.5); sarcoplasmic vesicles $\left(0.1 \mathrm{M} \mathrm{KCl}, 5 \mathrm{mM} \mathrm{MgCl}_{2}, 25 \mathrm{mM}\right.$ HEPES, $\mathrm{pH} 7.0$, $50 \mu \mathrm{M} \mathrm{CaCl}_{2}$ and $500 \mu \mathrm{M}$ ATP). The reactions were started after addition of $100 \mu \mathrm{M}$ decavanadate $(10 \mu \mathrm{M}$ of decameric vanadate specie) to the medium containing the samples $(1,2$, 4 and $8 \mu \mathrm{M}$ ) and the kinetics were followed during $60 \mathrm{~min}$.

\subsection{Light-scattering measurements}

F-actin depolymerization and G-actin polymerization were monitored, using a Jobin Yvon-Horiba FluoroMax3 spectrofluorimeter, at $25^{\circ} \mathrm{C}$, by the light scattering intensity change at $90^{\circ}$ with respect to the incident light, with both monochromators set at $546 \mathrm{~nm}$ [35], slits of $1.0 \mathrm{~nm}$ and adequate time acquisition setup. The reaction was started by the addition of the polymerization solution $(100 \mathrm{mM} \mathrm{KCl}, 2 \mathrm{mM} \mathrm{MgCl}$ ) to $8 \mu \mathrm{M}$ of G-actin in $2 \mathrm{mM}$ Tris, $0.2 \mathrm{mM} \mathrm{CaCl}, 10 \mu \mathrm{M}$ ATP (pH 7.5) in the absence or in the presence of the meta or decavanadate solutions $(1,2,4$ and $8 \mathrm{mM})$. The reactions were followed during $1 \mathrm{~h}$.

\subsection{NMR measurements}

${ }^{51} \mathrm{~V}$ NMR spectroscopy measurements were performed on a Bruker AM-400 MHz spectrometer at $105.2 \mathrm{MHz}$ equipped with a $5 \mathrm{~mm}$ multinuclear inverse probe. Spectra were acquired at $22^{\circ} \mathrm{C}$, using $0.5 \mathrm{ml}$ of samples containing $10 \% \mathrm{D}_{2} \mathrm{O}$, under the following conditions: $90^{\circ}$ pulse angle, spectral width $45,454 \mathrm{~Hz}$, acquisition time $0.086 \mathrm{~s}$, number of transients between 12,000 and 25,000 and relaxation delay $0.01 \mathrm{~s}$. For quantitative measurements all the spectral parameters were kept constant [29].

${ }^{51} \mathrm{~V}$ NMR chemical shifts are reported relative to an external reference of $\mathrm{VOCl}_{3}(0 \mathrm{ppm})$. NMR spectra of metavanadate $(1,2,4$ and $8 \mathrm{mM})$ and decavanadate $(1,2$, 4 and $8 \mathrm{mM}$ ) solutions were obtained in a reaction medium for G-actin polymerization containing $2 \mathrm{mM}$ Tris, $0.2 \mathrm{mM}$ $\mathrm{CaCl}_{2}, 100 \mathrm{mM} \mathrm{KCl}, 2 \mathrm{mM} \mathrm{MgCl}$, $\mathrm{pH} 7.5$ in the absence and presence of $20 \mu \mathrm{M}$ G-actin, $20 \mu \mathrm{M}$ F-actin or ATP $(1 \mathrm{mM})$ as desired. The ${ }^{51} \mathrm{~V}$ NMR line widths of the several free and bound vanadate resonances represent the widths at half-height after subtraction of $20 \mathrm{~Hz}$ used in line broadening. The concentrations of each vanadate species $V_{x}$ were calculated from the fractions of the total integrated areas using the following equation: $\left[V_{x}\right]=\left(A_{x} / A_{t}\right) \times\left(\left[V_{t}\right] / n\right)$, where $A_{x}$ corresponds to the area measured for the $x$ vanadate species with $n$ as the oligomer number (number of vanadium atoms), $A_{t}$ the sum of measured areas, and $\left[V_{t}\right]$ the total vanadate concentration, according to described elsewhere [29].

\section{Results and discussion}

\subsection{Decavanadate inhibition of G-actin polymerization}

Recently, it was described that decameric vanadate binds with high affinity near the back door of the catalytic site of myosin subfragment 1 , producing non-competitive inhibition of the F-actin stimulated S1 ATPase activity, without significant dissociation of the acto-S1 complex [7]. The possibility that the inhibition of the F-actin stimulated myosin ATPase activity could be due to decavanadate interactions with F-actin, instead with myosin, was excluded since the decameric vanadate concentrations used (up to $200 \mu \mathrm{M}$ total vanadate, i.e. nearly $20 \mu \mathrm{M}$ of decameric vanadate species) had no effect on the rate of G-actin polymerization or F-actin depolymerization. In this paper we have considered the possibility that at higher concentrations decameric vanadate can also interact with G-actin and F-actin.

Upon addition of decavanadate, it was verified an inhibition of the G-actin polymerization (Fig. 1). We mean by "decavanadate" a solution containing besides decameric vanadate species also monomeric vanadate species, as described in the following section. For decavanadate, the best curve that fits to experimental data point is an exponential decay for a second-order process, with $\mathrm{IC}_{50}$ inhibition values for G-actin polymerization of 0.17 and $3.7 \mathrm{mM}$ 


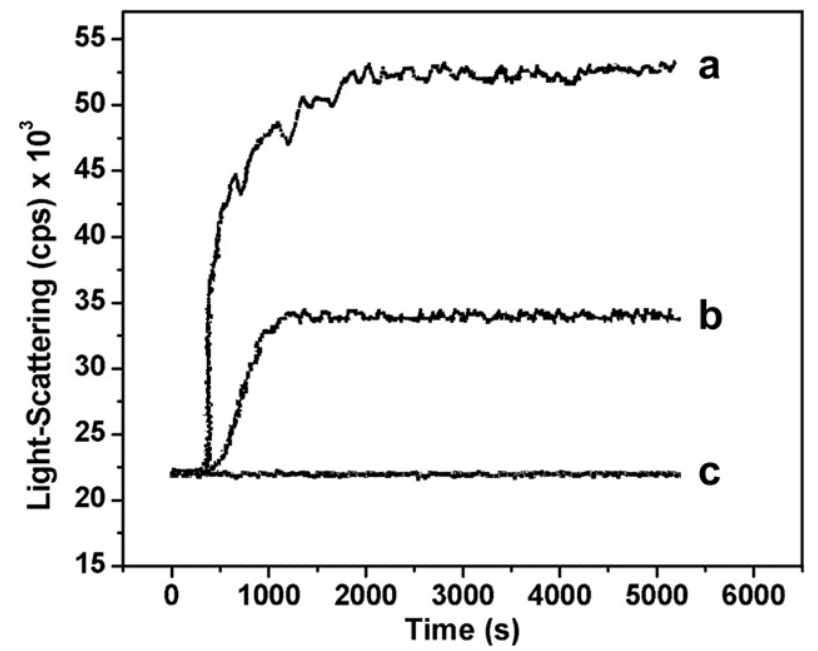

Fig. 1. Time course of $\mathrm{G}$-actin $(8 \mu \mathrm{M})$ polymerization (in Tris $2 \mathrm{mM}$, $\mathrm{CaCl}_{2} 0.2 \mathrm{mM}$, ATP $10 \mu \mathrm{M}, \mathrm{pH} 7.5$ ), monitored by light-scattering at $546 \mathrm{~nm}, 25^{\circ} \mathrm{C}$, in the absence (a) and in the presence of $4 \mathrm{mM}$ (b) and $8 \mathrm{mM}$ (c) of decavanadate (total vanadate concentration) added to the buffer just before starting the polymerization (with $\mathrm{KCl} 100 \mathrm{mM}, \mathrm{MgCl}_{2}$ $2 \mathrm{mM})$ at $25^{\circ} \mathrm{C}$.

for decavanadate, i.e., $17 \pm 2 \mu \mathrm{M}$ and $373 \pm 72 \mu \mathrm{M}$ for decameric vanadate species (V10) (Fig. 2a and b). The extent of G-actin polymerization was inhibited by decameric vanadate with an $\mathrm{IC}_{50}$ of $68 \pm 2 \mu \mathrm{M}$ (first-order process), whilst it induces F-actin depolymerization at a lower extent (data not shown). Conversely, no effect on actin polymerization and depolymerization was detected for $2 \mathrm{mM}$ concentration of "metavanadate" solution that contains V1, V2 and V4 vanadate species (Fig. 2a). Besides V10, tetrameric vanadate species may also contribute to the inhibition of actin polymerization as observed by combining kinetic with ${ }^{51} \mathrm{~V}$ NMR spectroscopy studies. In fact, increasing metavanadate concentration (from 2 to $8 \mathrm{mM}$ ), favors the formation of tetrameric vanadate species, as observed by NMR spectroscopy (Figs. 3 and 4). This vanadate solution inhibits G-actin polymerization, reaching $50 \%$ inhibition with $4 \mathrm{mM}$ total vanadium (Fig. 2). When ATP $(1 \mathrm{mM})$ was added to the reaction medium the inhibitory effects described above for decavanadate and metavanadate solutions were blocked.

During the actin polymerization process, ATP bound to G-actin is hydrolyzed to ADP that remains bound to Factin. By inhibiting G-actin polymerization, decameric vanadate may prevent microfilaments formation and Factin stimulation of myosin ATPase activity. The release of Pi induces depolymerization of F-actin whereas bound ADP.Pi stabilizes the filament [24]. On the other hand, formation of the ADP.Vi complex will produce stabilization of F-actin as previously suggested [24]. Taking into account these observations, and since the addition of ATP to the medium prevents the inhibitory effect of decameric vanadate on G-actin polymerization, it is suggested that decameric vanadate may inhibit G-actin polymerization through a mechanism involving the ATP binding site, a site
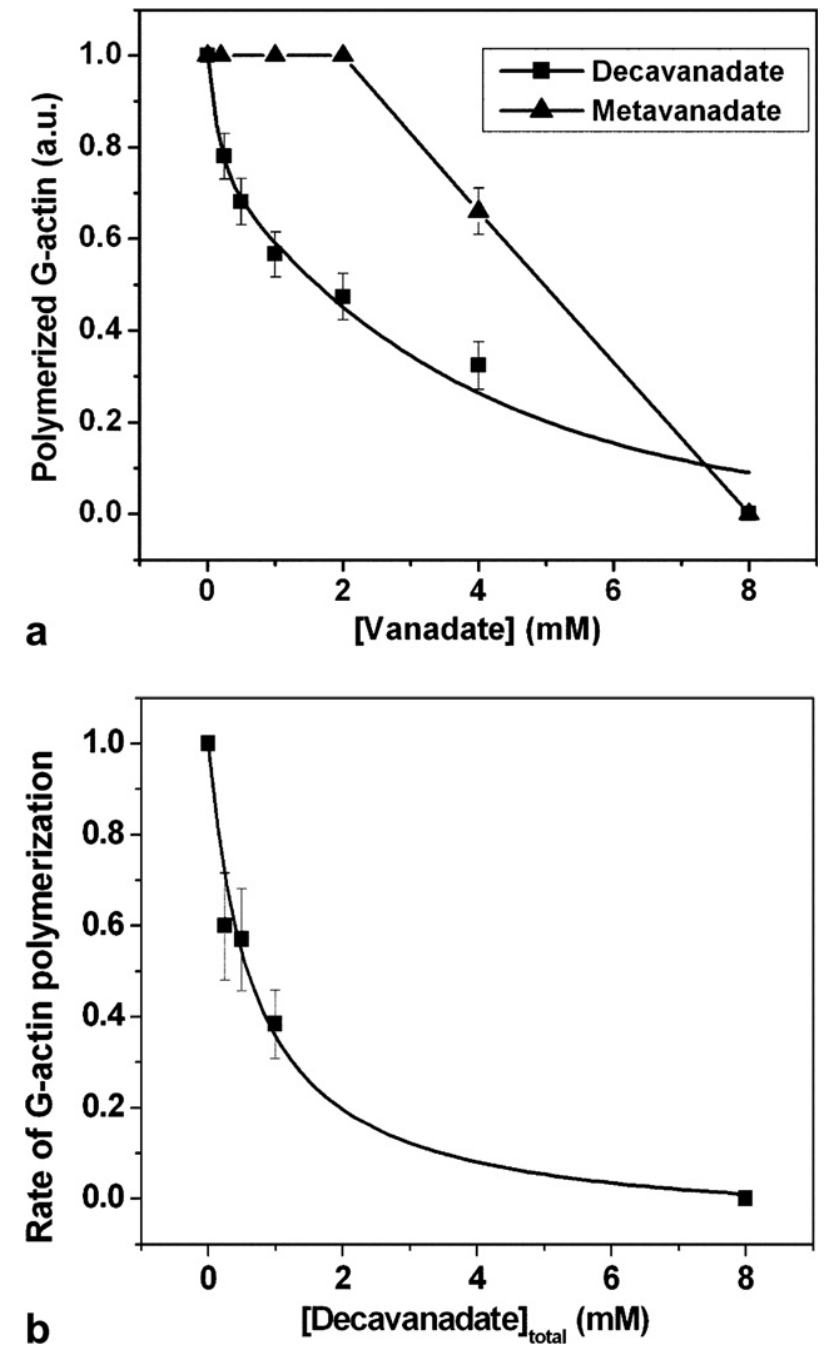

Fig. 2. G-actin $(8 \mu \mathrm{M})$ polymerization (in Tris $2 \mathrm{mM}, \mathrm{CaCl}_{2} 0.2 \mathrm{mM}$, ATP $10 \mu \mathrm{M}, \mathrm{pH}$ 7.5) was induced by $100 \mathrm{mM} \mathrm{KCl}, 2 \mathrm{mM} \mathrm{MgCl}$. (a) Extent of G-actin polymerization upon addition of various concentrations (total vanadate) of decavanadate $(\mathbf{\square})$ and metavanadate $(\boldsymbol{\Delta})$ relative to $\mathrm{G}$ actin (control). (b) Rate of G-actin polymerization in the presence of a range of concentrations (total vanadate) of decavanadate.

close to it or to a site that is exchange after subtract binding. By inhibiting G-actin polymerization, decameric vanadate eventually prevents microfilaments formation and F-actin stimulation of myosin ATPase activity. However, before attempting to understand the effects promoted by each individual vanadate species that may occur in the reaction medium, it is of primary importance to characterize precisely the vanadate solutions and the interactions with the system by using ${ }^{51} \mathrm{~V}$ NMR spectroscopy [17].

\subsection{NMR characterization of metavanadate and decavanadate solutions}

Although it is possible to obtain exclusively one vanadate species in a decavanadate stock solution, millimolar concentrations of metavanadate solutions contain ortho and metameric vanadate species as observed by NMR 

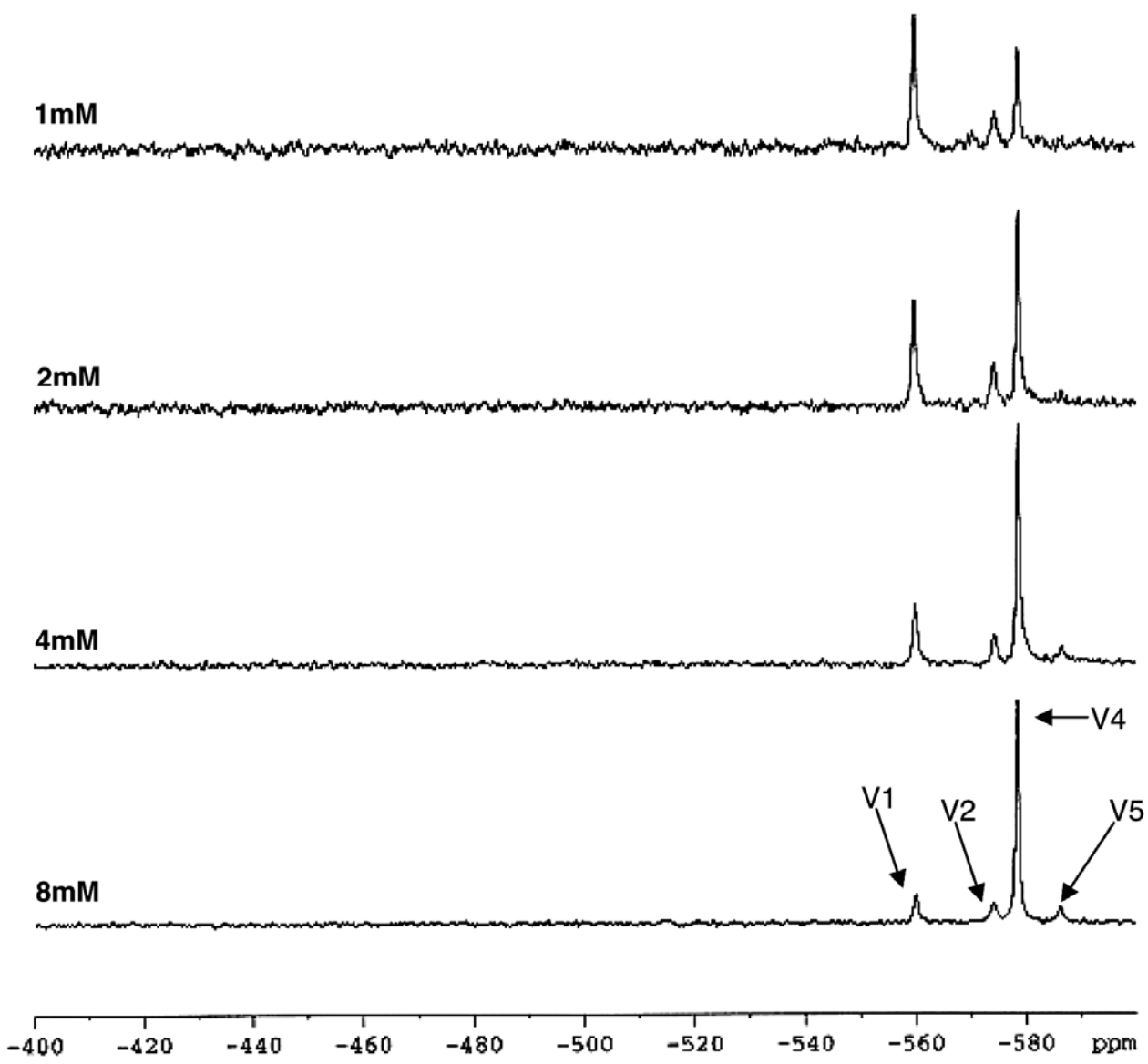

Fig. 3. $105.2 \mathrm{MHz}{ }^{51} \mathrm{~V}$ NMR spectra, at $22^{\circ} \mathrm{C}$, of different concentrations (total vanadate), namely $1,2,4$ and 8 mM of metavanadate in a medium containing $2 \mathrm{mM}$ Tris, $0.2 \mathrm{mM} \mathrm{CaCl}_{2}, 100 \mathrm{mM} \mathrm{KCl}, 2 \mathrm{mM} \mathrm{MgCl}_{2}, \mathrm{pH}$ 7.5. $\mathrm{V} 1$ and $\mathrm{V} 2 \mathrm{NMR}^{2}$ signals correspond, respectively, to monomeric $\left(\mathrm{H}_{2} \mathrm{VO}_{4}^{-}\right)$ and dimeric $\left(\mathrm{HV}_{2} \mathrm{O}_{7}^{3-}\right.$ and $\left.\mathrm{H}_{2} \mathrm{~V}_{2} \mathrm{O}_{7}^{2-}\right)$ vanadate species irrespective of the protonation state, whereas $\mathrm{V} 4$ and $\mathrm{V} 5$ correspond to cyclic tetrameric $\left(\mathrm{V}_{4} \mathrm{O}_{12}^{4-}\right)$ and pentameric $\left(\mathrm{V}_{5} \mathrm{O}_{15}^{5-}\right)$ vanadate species.

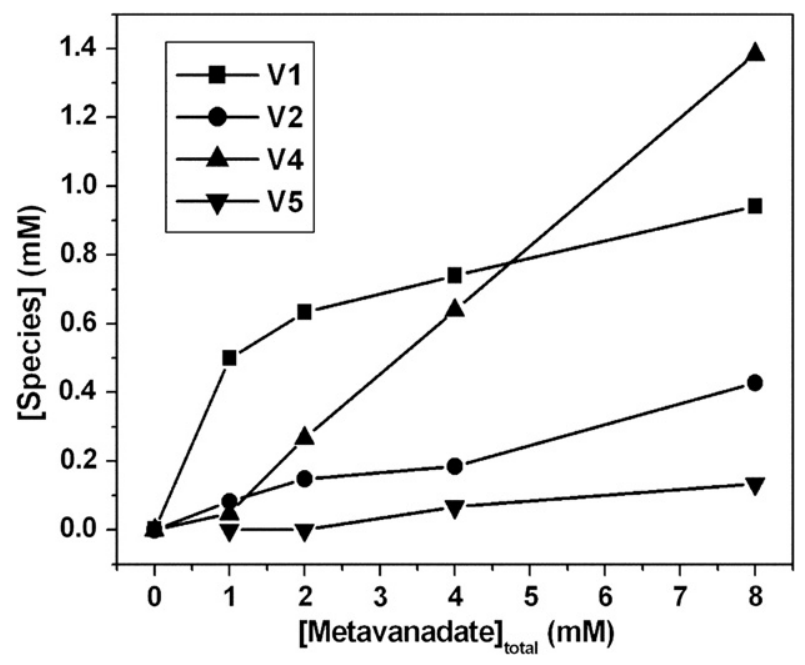

Fig. 4. Vanadium (V) species composition of the metavanadate solutions used in the assays. A series of ${ }^{51} \mathrm{~V}$ NMR spectra of the metavanadate solutions were recorded at concentrations up to $8 \mathrm{mM}$, in a medium containing $2 \mathrm{mM}$ Tris, $0.2 \mathrm{mM} \mathrm{CaCl}_{2}, 100 \mathrm{mM} \mathrm{KCl}, 2 \mathrm{mM} \mathrm{MgCl}_{2}, \mathrm{pH}$ 7.5 , at $22^{\circ} \mathrm{C}$. The concentrations of each vanadium $(\mathrm{V})$ species were calculated from the fractions of the total integrated areas observed in the spectra. spectroscopy $[17,36]$. Only for metavanadate concentrations at the micromolar range, orthovanadate species are exclusively present [14]. ${ }^{51} \mathrm{~V}$ NMR spectra of nominal $4 \mathrm{mM}$ metavanadate solution that inhibits G-actin polymerization by $50 \%$, contains $740 \mu \mathrm{M}$ monomeric (V1), $185 \mu \mathrm{M}$ dimeric (V2), $639 \mu \mathrm{M}$ tetrameric (V4) and $67 \mu \mathrm{M}$ pentameric (V5) species (Fig. 4). A significant increase of V4 concentration is observed for higher concentrations of vanadate study (4 and $8 \mathrm{mM}$ ) (Fig. 4).

Conversely to metavanadate solutions, which have several vanadate species in rapid equilibrium, decavanadate solutions (2-8 mM) contain decameric vanadate species and monomeric vanadate species (Fig. 5). ${ }^{51} \mathrm{~V}$ NMR spectra of decavanadate solutions (from 2 to $8 \mathrm{mM}$ total vanadium) display signals from decameric vanadate species: V10A at $-515 \mathrm{ppm}, \mathrm{V} 10 \mathrm{~B}$ at $-500 \mathrm{ppm}$ and $\mathrm{V} 10 \mathrm{C}$ at -424 ppm and also a signal ascribed to monomeric species at $-560 \mathrm{ppm}$. In the decavanadate solutions, the concentration of decameric vanadate increases linearly with total vanadate concentration, whereas monomeric vanadate remains approximately constant (Fig. 6). Therefore, when the stock solution of decavanadate is diluted, for instance, into the reaction medium at low concentrations $(2 \mathrm{mM}$ 

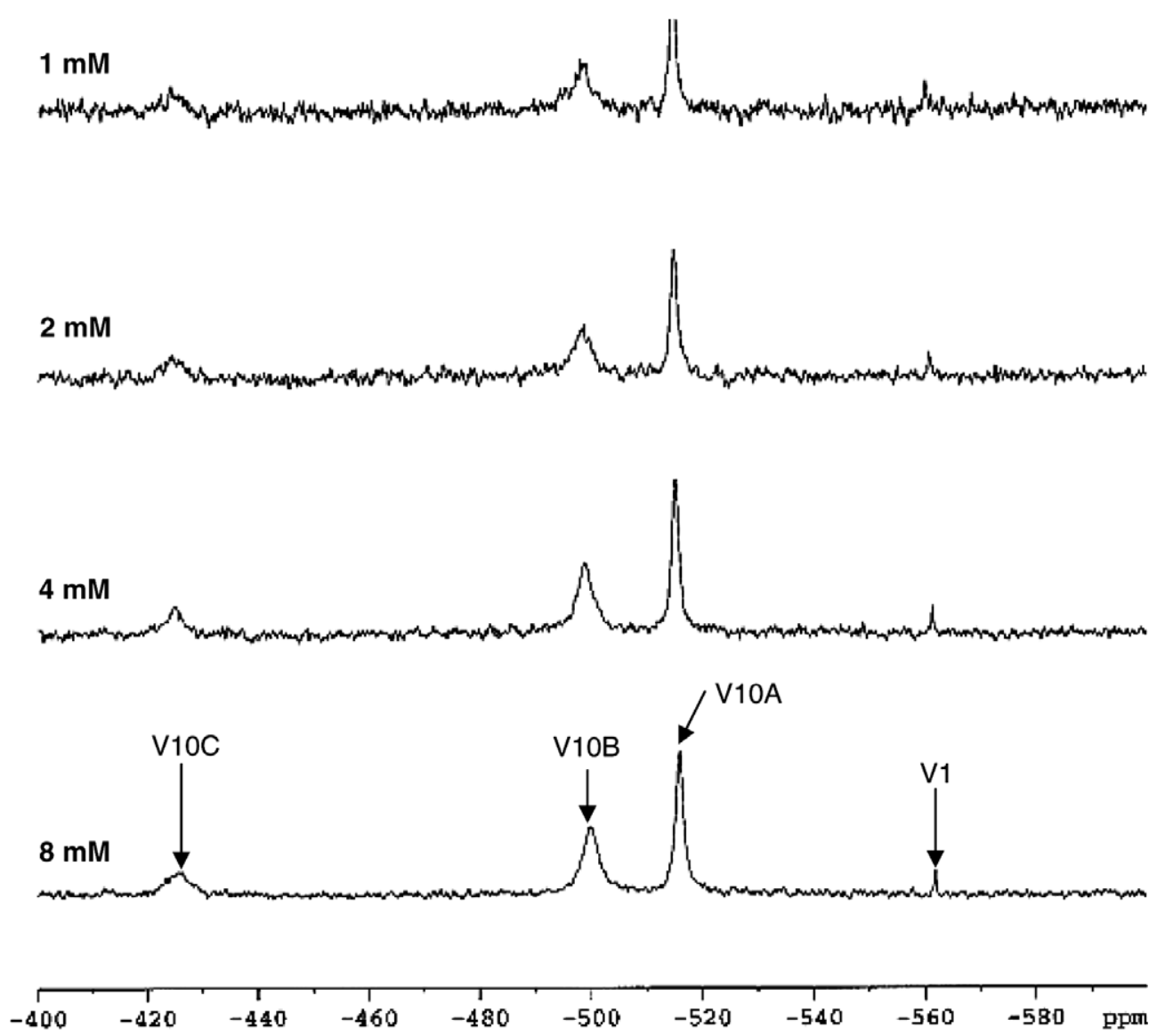

Fig. 5. $105.2 \mathrm{MHz}{ }^{51} \mathrm{~V}$ NMR spectra, at $22{ }^{\circ} \mathrm{C}$, of different concentrations (total vanadate), namely $1,2,4$ and $8 \mathrm{mM}$ of decavanadate in a medium containing $2 \mathrm{mM}$ Tris, $0.2 \mathrm{mM} \mathrm{CaCl}_{2}, 100 \mathrm{mM} \mathrm{KCl}, 2 \mathrm{mM} \mathrm{MgCl}_{2}, \mathrm{pH}$ 7.5. V1 NMR signal corresponds to monomeric $\left(\mathrm{H}_{2} \mathrm{VO}_{4}^{-}\right)$, while $\mathrm{V} 10 \mathrm{~A}$, $\mathrm{V} 10 \mathrm{~B}$ and V10C signals correspond, respectively, to the $\mathrm{V}(2), \mathrm{V}(1)$ and $\mathrm{V}(3)$ vanadium atoms in the decameric vanadate specie $\left(\mathrm{V}_{10} \mathrm{O}_{28}^{6-}\right)$.

total vanadium equivalent to about $200 \mu \mathrm{M}$ decameric species), ${ }^{51} \mathrm{~V}$ NMR spectra shows an additional signal from monomeric vanadate, that is, decameric vanadate is partial disintegrated or decomposed into monomeric vanadate species. This observation means that the solution contains besides decameric vanadate $(180 \mu \mathrm{M})$ also monomeric vanadate $(200 \mu \mathrm{M})$, that is, about $1: 1$ stoichiometry of decameric and monomeric vanadate species. However, upon increasing decavanadate concentration (from 2 to $8 \mathrm{mM}$ ) monomeric vanadate concentration remained approximately constant (Fig. 6).

\subsection{UV/Vis characterization of decavanadate solutions}

In contrast to the labile oxovanadates, which interconvert on the time scale of milliseconds to seconds, decameric vanadate has very slow decomposition kinetics upon dilution. The kinetics of dissociation of decameric species, at $25^{\circ} \mathrm{C}$, in the reaction medium used for G-actin polymerization, assessed by measurements of the absorption at $400 \mathrm{~nm}$ confirms a first-order kinetic process, with an half-time of $5 \mathrm{~h}$ (measured with $100 \mu \mathrm{M}$ total vanadate concentration, i.e. $10 \mu \mathrm{M}$ decameric vanadate species).

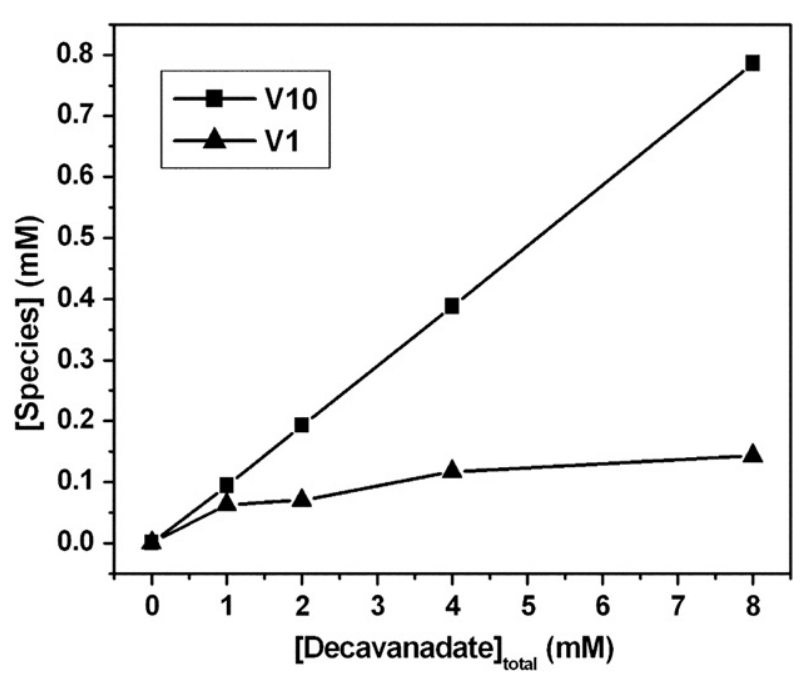

Fig. 6. Vanadium (V) species composition of the decavanadate solutions used in the assays. A series of ${ }^{51} \mathrm{~V}$ NMR spectra of the metavanadate solutions were recorded at concentrations up to $8 \mathrm{mM}$, in a medium containing $2 \mathrm{mM}$ Tris, $0.2 \mathrm{mM} \mathrm{CaCl}_{2}, 100 \mathrm{mM} \mathrm{KCl}, 2 \mathrm{mM} \mathrm{MgCl}$, $\mathrm{pH}$ 7.5 , at $22{ }^{\circ} \mathrm{C}$. The concentrations of each vanadium (V) species were calculated from the fractions of the total integrated areas observed in the spectra. 
Therefore, this complex oxoanion remains relatively stable during the period used in the light-scattering experiments (1 h).

Although NMR spectroscopy is an essential technique for the analysis of vanadate oligomers composition, about $1 \mathrm{~h}$ of acquisition time is needed to obtain a spectrum of a $1 \mathrm{mM}$ decavanadate solution; thus, NMR cannot do the kinetic of the decomposition of decameric species. However, the disappearance of decameric vanadate species can be easily followed by UV/Vis spectroscopy. UV/Vis spectra of several decavanadate solutions were obtained immediately after dilution (from 0.025 to $1 \mathrm{mM}$ total vanadate) and in the experimental medium used in the polymerization studies. An extinction coefficient of $\varepsilon_{400}=645 \mathrm{M}^{-1} \mathrm{~cm}^{-1}$ was obtained for the decameric vanadate oligomer. The decameric species can be also evaluated by second derivative of the UV/Vis spectra of "decavanadate" solutions (Fig. 7). As observed in Fig. 7, "decavanadate" concentration is proportional to the increase of the 2nd derivative bands at 358 and $400 \mathrm{~nm}$ ascribed to decameric species. A linear correlation is obtained from 10 to $100 \mu \mathrm{M}$ of decameric vanadate, i.e. from 100 to $1 \mathrm{mM}$ total vanadate concentration (Fig. 8). Therefore, in the experimental conditions used in this study, total decameric vanadate concentrations as low as $10 \mu \mathrm{M}$ can be detected by $\mathrm{UV} / \mathrm{Vis}$ spectroscopy.

\subsection{Stabilization of decameric vanadate by G-actin under polymerization}

It was observed that at $25^{\circ} \mathrm{C}$, the half-life time of decameric vanadate $(10 \mu \mathrm{M})$ increases up to 5 -fold, from 5 to $27 \mathrm{~h}$, in the presence of increasing concentrations of Gactin in the medium used to induce G-actin polymerization, and for a stoichiometric concentration of ATP (Fig. 9, black square). The increase of the half-life of decameric vanadate upon increasing the protein concentration can

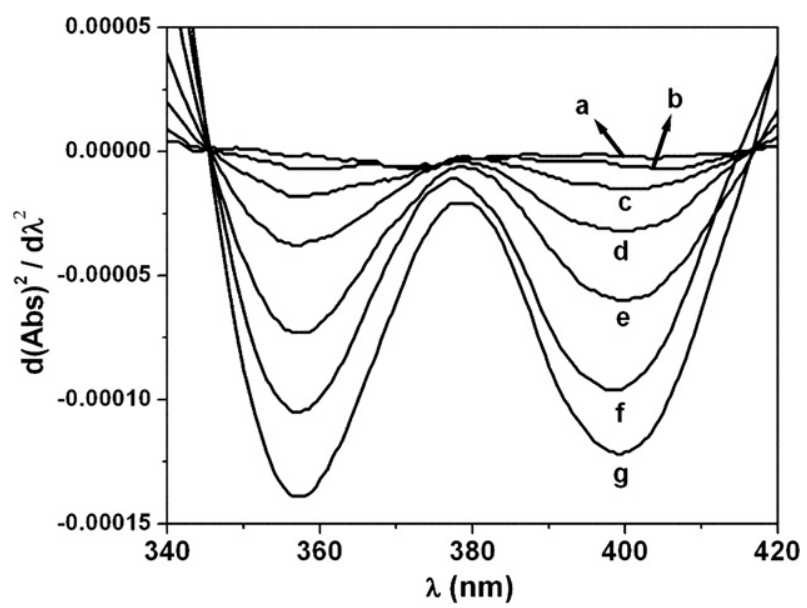

Fig. 7. Second derivative of UV/Vis absorption spectrum of decavanadate (in $2 \mathrm{mM}$ Tris, $0.2 \mathrm{mM} \mathrm{CaCl} 2,100 \mathrm{mM} \mathrm{KCl}, 2 \mathrm{mM} \mathrm{MgCl}_{2}, \mathrm{pH} 7.5$ ) at $25^{\circ} \mathrm{C}$. Decavanadate concentrations (total vanadate): (a) $0.025 \mathrm{mM}$; (b) $0.05 \mathrm{mM}$; (c) $0.1 \mathrm{mM}$; (d) $0.25 \mathrm{mM}$; (e) $0.5 \mathrm{mM}$; (f) $0.75 \mathrm{mM}$; (g) $1.0 \mathrm{mM}$.

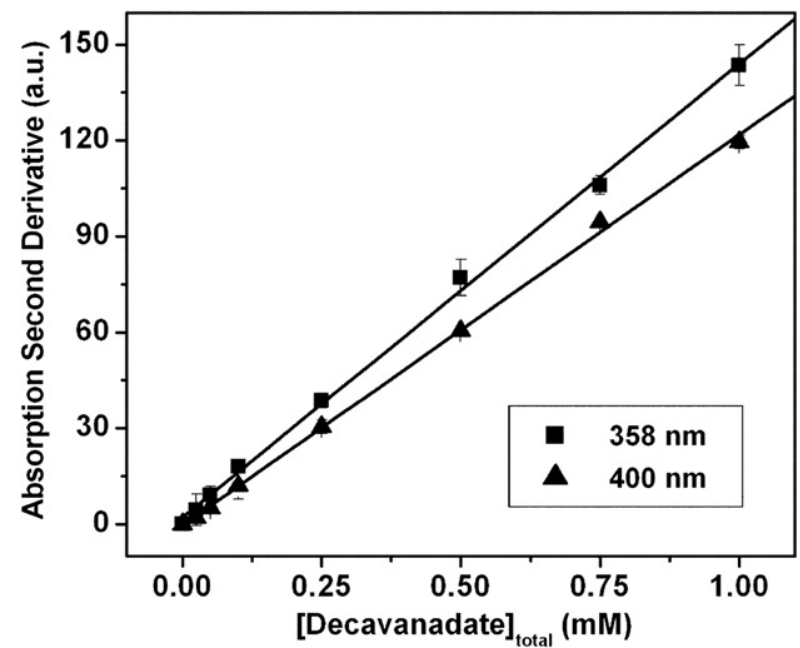

Fig. 8. Second derivative of UV/Vis absorption values (arbitrary units) at 358 and at $400 \mathrm{~nm}$, as a function of decavanadate concentration (total vanadate).

be rationalized in terms of a complex formation between decameric vanadate and G-actin. Considering two equilibrium reactions, one between $\mathrm{V} 10$ and $\mathrm{V} 1$ and the other between V10 and the protein, and taking into account that the first one is much slower (time scale of hours) than the second (time scale of seconds or minutes at most) we can deduce that the velocity of decomposition of decameric vanadate species is inversely proportional to the increase of the protein concentration [37-39].

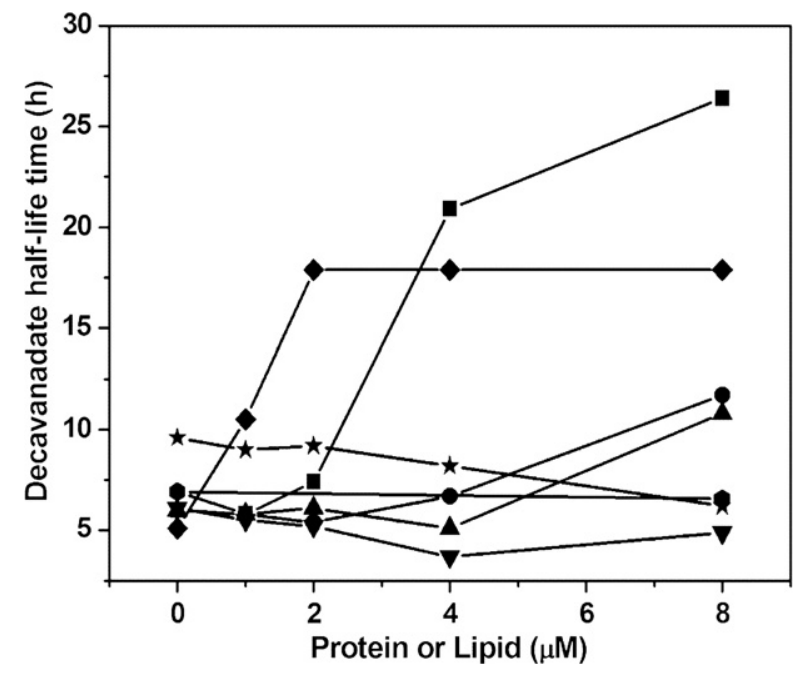

Fig. 9. Decavanadate (100 $\mu \mathrm{M}$ total vanadate, $10 \mu \mathrm{M}$ decameric vanadate species) half-life time in presence of: ( $\boldsymbol{\square})$ G-actin (in $2 \mathrm{mM}$ Tris, $0.2 \mathrm{mM}$ $\mathrm{CaCl}_{2}, 10 \mu \mathrm{M}$ ATP, $100 \mathrm{mM} \mathrm{KCl}, 2 \mathrm{mM} \mathrm{MgCl}$, pH 7.5); (•) G-actin (in $2 \mathrm{mM}$ Tris, $0.2 \mathrm{mM} \mathrm{CaCl}_{2}, 0.2 \mathrm{mM} \mathrm{ATP}, 100 \mathrm{mM} \mathrm{KCl}, 2 \mathrm{mM} \mathrm{MgCl} 2, \mathrm{pH}$ 7.5); ( G-actin (in $2 \mathrm{mM}$ Tris, $0.2 \mathrm{mM} \mathrm{CaCl} 2,0.2 \mathrm{mM} \mathrm{ATP,} \mathrm{pH} 7.5$ ); (ム) F-actin (in $2 \mathrm{mM}$ Tris, $0.2 \mathrm{mM} \mathrm{CaCl}, 10 \mu \mathrm{M}$ ATP, $100 \mathrm{mM} \mathrm{KCl}$, $2 \mathrm{mM} \mathrm{MgCl}_{2}, \mathrm{pH} 7.5$ ); ( $) \mathrm{S} 1$ (in $2 \mathrm{mM}$ Tris, $0.2 \mathrm{mM} \mathrm{CaCl} 2,0.2 \mathrm{mM}$ ATP, pH 7.5); ( ) SRV (in $0.1 \mathrm{M} \mathrm{KCl}, 5 \mathrm{mM} \mathrm{MgCl} 2,25 \mathrm{mM}$ HEPES, $50 \mu \mathrm{M} \mathrm{CaCl}_{2}, 500 \mu \mathrm{M}$ ATP, pH 7.0); ( $\star$ ) Liposomes (POPC multilamellar vesicles in $2 \mathrm{mM}$ Tris, $\mathrm{pH} 7.5$ ). 
Almost a plateau of the half-life time was reached for Gactin concentration between 4 and $8 \mu \mathrm{M}$, and for $10 \mu \mathrm{M}$ of decameric vanadate species, thus suggesting that the Gactin:V10 stoichiometry is approximately one or higher, contrarily to sarcoplasmic reticulum calcium ATPase with about five decameric vanadate molecules per calcium pump (Fig. 9, black lozenge).

The addition of ATP $(200 \mu \mathrm{M})$ to the medium prevents the inhibition of G-actin polymerization by V10 and also decreased the half-life time of decameric vanadate species, from 27 to $10 \mathrm{~h}$ (compare black square with black circle). A similar pattern was also obtained for the decameric half-life time upon increasing F-actin concentration or G-actin in the presence of ATP (Fig. 9, compare black up triangle and black circle), suggesting that both the forms of actin, F-actin filaments or the G-actin.ATP, may behave as a similar target for decameric vanadate species. On the other hand, no changes on decameric vanadate half-life were observed upon G-actin $(8 \mu \mathrm{M})$ addition in an experimental medium that does not induced polymerization (black hexagon), pointing out that V10 does not bind to the ATP binding site by itself. Taking into consideration that the highest half-life value for decameric $(10 \mu \mathrm{M})$ decomposition was observed when G-actin is under polymerization conditions (Fig. 9, black square), it implies that decameric vanadate stabilization may be favored by the occurrence of G-actin polymerization for equimolar ATP concentrations. Furthermore, decameric vanadate stabilization may be favored by the occurrence of G-actin polymerization/depolymerization equilibrium. These results suggest two possibilities for decameric vanadate interaction with G-actin: (i) through binding to G-actin-ATP complex at binding site close to ATP binding site or (ii) at another binding site. As in Factin filament the ATP binding site is not accessible, it is most likely that V10 binds to a different binding site from ATP. It is suggested two possibilities of decameric vanadate interaction with G-actin: through binding to Gactin-ADP.Pi complex at binding site close to ATP binding site or to a site that is exchanged after subtract binding. However, studies are currently in course in order to clearly understand the interaction of decameric vanadate species with actin.

It is recognized that decavanadate interacts with many enzymes. To gain a better understanding of the above observations we have studied the effects of other proteins in the stability of decameric vanadate, in particular those known to be inhibited by decavanadate and related with the regulation of muscle contraction, namely the contractile protein myosin and the transmembrane protein $\mathrm{Ca}^{2+}$. ATPase which plays a major role in the decrease of cytosolic calcium leading to muscle relaxation. It was also observed that decameric vanadate is also stabilized by the calcium pump from sarcoplasmic reticulum whereas no effects were observed in the presence of liposomes or myosin subfragment-1 (Fig. 9). The absence of effect upon addition of liposomes indicates that stabilization with SRV is due to the membrane-bound proteins, not by the lipid bilayers. It is to be noted that in the sarcoplasmic reticulum vesicles (SRV), besides the calcium pump, other proteins may contribute for decameric vanadate stabilization since the vesicles contain also significant amounts of calsesquestrin $(10 \%)$ and glycogen phosphorylase $(16 \%)$, as observed by SDS-PAGE (results not shown).

\section{5. ${ }^{51} V N M R$ analysis of the interaction of G-actin with decavanadate}

As it was described above, the rate of decomposition of decameric vanadate is much slower in the presence of Gactin than in the presence of F-actin. In order to understand the interactions of the different forms of actin with V10 we carried out NMR experiments indicated below. Upon addition of G-actin $(20 \mu \mathrm{M})$ to $2 \mathrm{mM}$ of decavanadate, in the presence of $10 \mu \mathrm{M}$ ATP, the ${ }^{51} \mathrm{~V}$ NMR signal at $-515 \mathrm{ppm}$ broadens (from 167 to $205 \mathrm{~Hz}$ ) and its intensity decreases (Fig. 10a and b). The presence of higher concentrations of ATP in the medium $(0.2 \mathrm{mM})$ did not significantly change the NMR spectra upon addition of G-actin being the V10 signals very similar in both conditions point out that by increasing the concentration of the protein natural ligand it does not prevent or favored V10 interaction (Fig. 10c). However, the addition of Factin to decavanadate solutions (Fig. 10d) produced a stronger broadening (from 167 to $318 \mathrm{~Hz}$ (1.9-fold) in the V10A signal from the decameric vanadate species, whereas the decrease in the intensities of the decameric vanadate resonances is more pronounced in comparison with the addition of G-actin (Fig. 10b). The results observed for $\mathrm{F}$-actin are in good agreement with the 1.5 -fold broadening of V10 NMR signal in the presence of $20 \mu \mathrm{M}$ of F-actin [40]. Apparently, G-actin does not broaden decameric vanadate signals unless there is enough time to induce the formation of F-actin (Fig. 10e). In this experimental condition, the NMR spectra were obtained 90 min after G-actin addition in the medium that induces its polymerization into F-actin. The V10 signals became broadened and the intensity decreases in a similar pattern observed for F-actin, although to a lower extent, whereas a pronounced increase (3-fold) of monomeric vanadate species is observed (Fig. 10e).

It is to be noted that if it occurs total disintegration or decomposition of decameric vanadate species, for $2 \mathrm{mM}$ decavanadate concentration, besides monomeric vanadate species, V1, others vanadate oligomers may appear in solution such as divanadate (V2) and tetravanadate (V4), as observed by NMR, while the color of the vanadate solution changes from pale yellow to colorless (not shown). However, this process, as it was described above, is very slow not allowing observing the total decomposition of decavanadate in the presence of the proteins since they denature for such a long incubation time.

Our results do not allow to clearly define the effects promoted by each individual vanadate species that occur simultaneously in solution, or to completely define the 

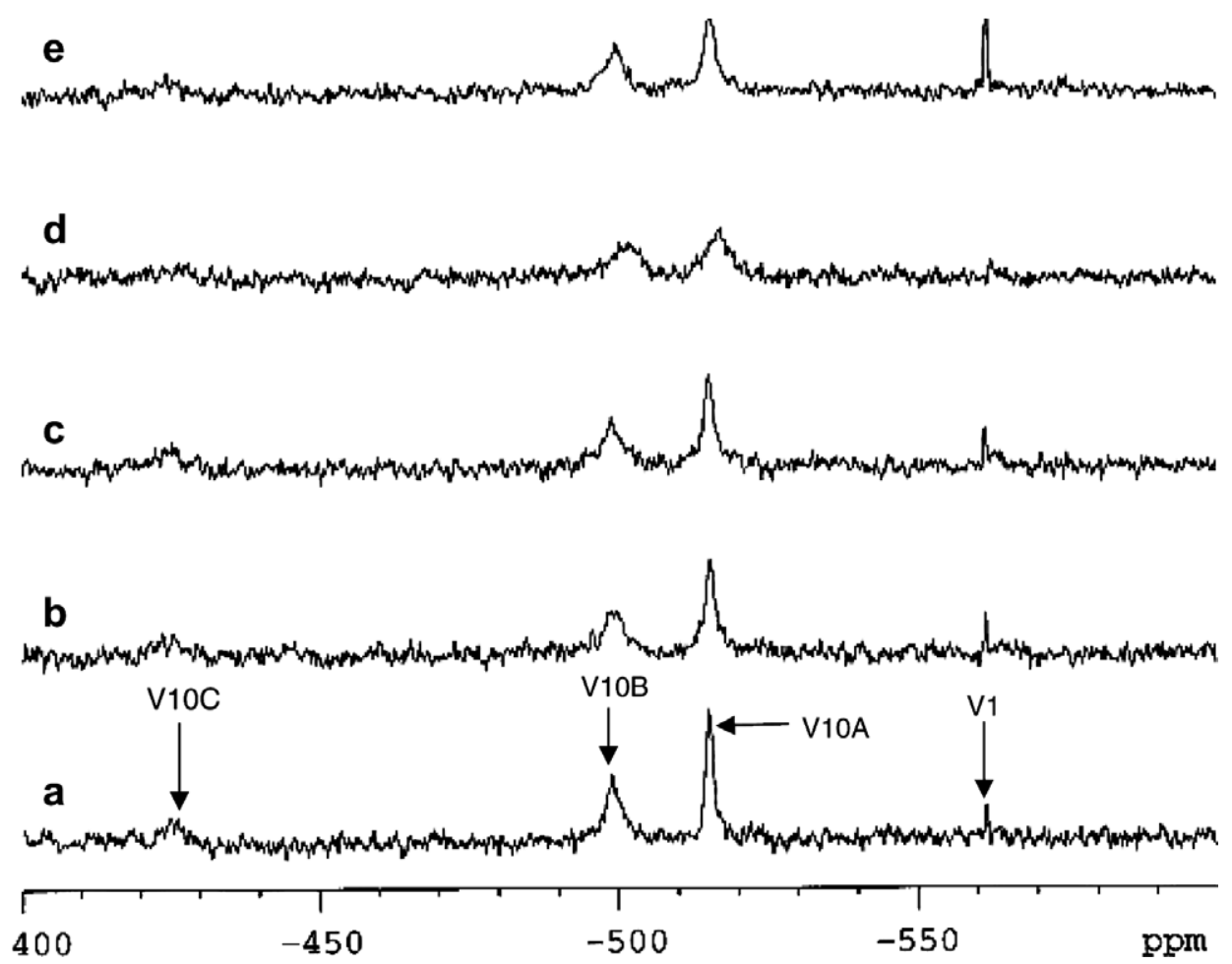

Fig. 10. $105.2 \mathrm{MHz}^{51} \mathrm{~V}$ NMR spectra, at $22^{\circ} \mathrm{C}$, of decavanadate $2 \mathrm{mM}$ (total vanadate) in (a) $2 \mathrm{mM} \mathrm{Tris,} 0.2 \mathrm{mM} \mathrm{CaCl}_{2}, 100 \mathrm{mM} \mathrm{KCl}^{2} 2 \mathrm{mM} \mathrm{MgCl}$, $\mathrm{pH}$ 7.5 and with: (b) $20 \mu \mathrm{M}$ G-actin plus $10 \mu \mathrm{M}$ ATP, (c) $20 \mu \mathrm{M}$ G-actin plus $0.2 \mathrm{mM}$ ATP, (d) $20 \mu \mathrm{M}$ F-actin plus $10 \mu \mathrm{M}$ ATP, and (e) solution b measured after 90 min. V1 NMR signal corresponds to monomeric $\left(\mathrm{H}_{2} \mathrm{VO}_{4}^{-}\right)$, while $\mathrm{V} 10 \mathrm{~A}, \mathrm{~V} 10 \mathrm{~B}$ and $\mathrm{V} 10 \mathrm{C}$ signals correspond, respectively, to the $\mathrm{V}(2)$, $\mathrm{V}(1)$ and $\mathrm{V}(3)$ vanadium atoms in the decameric vanadate specie $\left(\mathrm{V}_{10} \mathrm{O}_{28}^{6-}\right)$.

interactions of decavanadate with actin. It was clear, however, that decameric vanadate inhibits G-actin polymerization.

In conclusion, it is suggested that "decavanadate" interaction with G-actin is favored during G-actin polymerization, stabilizes decameric vanadate species and induces inhibition of G-actin polymerization. Decameric vanadate modulates the actin polymerization/depolymerization equilibrium which is different to the one described for monomeric vanadate. It is proposed that decameric vanadate stabilization by cytoskeleton and membrane-bound proteins can account, at least in part, for decavanadate toxicity in biological systems.

\section{Abbreviations}

ATP adenosine $5^{\prime}$-triphosphate

ADP adenosine 5'-diphosphate

F-actin polymerized form of monomeric actin

G-actin actin monomeric form

Hepes 4-(2-hydroxyethyl)-1-piperazine ethane sulfonic acid

M myosin

$\mathrm{P}_{\mathrm{i}} \quad$ inorganic phosphate

POPC 1-palmitoyl-2-oleoyl-sn-glycero-3-phosphocholine S1 myosin subfragment 1

SDS sodium dodecyl sulfate
Tris tris(hydroxymethyl)aminomethane

SRV sarcoplasmic reticulum vesicles

$\mathrm{UV} / \mathrm{Vis}$ ultraviolet/visible

V1 orthovanadate or monomeric vanadate species

V10 decameric vanadate species

V2 dimeric vanadate species

V4 tetrameric vanadate specie

V5 pentameric vanadate species

\section{Acknowledgments}

This work has been supported by Joint Spanish-Portuguese Grant HP2004-0080 (to C.G.-M. and M.A.), by POCTI program funded through FEDER for the research project 38191/QUI/2001 (to M.A.), and by Grant 3PR05A078 of the Junta de Extremadura (to C.G.-M.). Dr. T. Tiago is the recipient of a post-doctoral fellowship (SFRH/BPD/20777/2004) from the Portuguese Foundation for Science and Technology (FCT).

\section{References}

[1] R.J. French, P.J.H. Jones, Life Sci. 52 (1993) 339-346.

[2] B.F. Harland, B.A. Harden-Williams, J. Am. Diet. Assoc. 94 (1994) 891-894. 
[3] J.O. Nriagu, in: J.O. Nriagu (Ed.), Vanadium in the Environment Part 1: Chemistry and Biochemistry, John Wiley \& Sons, Inc., New York, 1998.

[4] L. Josephson, L.C. Cantley Jr., Biochemistry 16 (1977) 4572-4578.

[5] L.C. Cantley Jr., L. Josephson, R. Warner, M. Yanagisawa, C. Lechene, G. Guidotti, J. Biol. Chem. 252 (1977) 7421-7423.

[6] C.C. Goodno, Proc. Natl. Acad. Sci. USA 76 (1979) 2620-2624.

[7] T. Tiago, M. Aureliano, C. Gutiérrez-Merino, Biochemistry 43 (2004) $5551-5561$.

[8] L. Petterson, I. Andersson, B. Hedman, Chem. Scri. 25 (1985) 309317.

[9] D.C. Crans, Comment Inorg. Chem. 16 (1993) 1-33.

[10] A.M. Amado, M. Aureliano, P.J. Ribeiro-Claro, J.J.C. Teixeira-Dias, J. Raman Spectrosc. 24 (1993) 669-703.

[11] N.D. Chasteen, Struct. Bond. 53 (1983) 105-138.

[12] D.C. Crans, Comment Inorg. Chem. 16 (1993) 35-76.

[13] P.J. Stankiewicz, A.S. Tracey, D.C. Crans, in: A. Sigel, H. Sigel (Eds.), Metal Ions in Biological Systems, vol. 31, Marcel Dekker, New York, 1995, pp. 287-323.

[14] M. Aureliano, V.M.C. Madeira, Adv. Environ. Sci. Technol. 30 (1998) 333-358.

[15] D.C. Crans, C.D. Rithner, L.A. Theisen, J. Am. Chem. Soc. 112 (1990) 2901-2908.

[16] P. Kalyani, T. Ramasarma, Arch. Biochem. Biophys. 297 (1992) 244 252.

[17] M. Aureliano, R.M.C. Gândara, J. Inorg. Biochem. 99 (2005) 979 985.

[18] T. Tiago, M. Aureliano, C. Gutiérrez-Merino, J. Fluorescence 12 (2002) 87-90.

[19] M. Farahbakhsh, P. Kögerler, H. Schmidt, D. Rehder, Inorg. Chem. Commun. 1 (1998) 111-114.

[20] M. Aureliano, N. Joaquim, A. Sousa, H. Martins, J.M. Coucelo, J. Inorg. Biochem. 90 (2002) 159-165.

[21] G. Borges, P. Mendonça, N. Joaquim, M. Aureliano, J.M. Coucelo, Arch. Environ. Contam. Toxicol. 45 (2003) 415-422.
[22] R.M.C. Gândara, S.S. Soares, H. Martins, C. Gutiérrez-Merino, M. Aureliano, J. Inorg. Biochem. 99 (2005) 1238-1244.

[23] S.S. Soares, H. Martins, M. Aureliano, Arch. Environ. Contam. Toxicol. 50 (2006) 60-64.

[24] C. Combeau, M.F. Carlier, J. Biol. Chem. 263 (1988) 17429-17436.

[25] E. Brener, S. Rubinstein, G. Cohen, K. Shternall, J. Rivlin, H. Breitbart, Biol. Reprod. 68 (2003) 837-845.

[26] M. Anaya-Ruiz, J.L. Perez-Santos, P. Talamas-Rohana, Int. J. Parasitol. 33 (2003) 663-670.

[27] L.S. Capella, J.S.M. Alcantara, V. Moura-Neto, A.G. Lopes, M.A.M. Capella, Tumor Biol. 21 (2000) 54-62.

[28] K.V. Thiman, R. Biradivolu, Protoplasma 183 (1994) 5-9.

[29] M. Aureliano, T. Tiago, R.M.C. Gândara, A. Sousa, A. Moderno, M. Kaliva, A. Salifoglou, R.O. Duarte, J.J.G. Moura, J. Inorg. Biochem. 99 (2005) 2355-2361.

[30] J.D. Pardee, J.A. Spudich, Methods Enzymol. 85 (1982) 164-181.

[31] D.J. Gordon, Y.Z. Yang, E.D. Korn, J. Biol. Chem. 251 (1976) 7474 7479.

[32] E.M.V. Pires, S.V. Perry, M.A.W. Thomas, FEBS Lett. 41 (1974) $292-296$.

[33] A.G. Gornall, C.J. Bardawill, M.M. Davis, J. Biol. Chem. 177 (1949) $751-766$.

[34] F. Szoka Jr., D. Papahadjopoulos, Ann. Rev. Biophys. Bioeng. 9 (1980) 467-508.

[35] J.A. Cooper, T.D. Pollard, Methods Enzymol. 85 (1982) 182-210.

[36] M. Aureliano, V.M.C. Madeira, Biochim. Biophys. Acta 1221 (1994) $259-271$.

[37] J.I. Steinfeld, J.S. Francisco, W.L. Hase, Chemical Kinetics and Dynamics, second ed., Prentice-Hall, Upper Saddle River, NJ, 1998.

[38] H.H. Perkampus, UV-Vis Spectroscopy and its Applications, Springer, New York, 1992.

[39] S. Takegami, K. Kitamura, T. Kitade, A. Kitagawa, K. Kawamura, Chem. Pharm. Bull. 51 (2003) 1056-1059.

[40] T. Tiago, M. Aureliano, J.J.G. Moura, J. Inorg. Biochem. 98 (2004) 1902-1910. 